\title{
A case study of management of academic journals effect improvement in the context of new media
}

\author{
Zhen Weifeng ${ }^{1}$, Yu Yakun², Bu Yamin*3 \\ ${ }^{1}$ School of Journalism and Communication, Minjiang University, Fuzhou, Fujian 350108; \\ ${ }^{2}$ freelance researcher; \\ ${ }^{3}$ Huihua College of Hebei Normal University, Shijiazhuang, Hebei, Shijiazhuang, 050091
}

\begin{abstract}
Purpose]: To understand the factors those influence the dissemination effect of academic journals after the rise of new media.[Methods]: A questionnaire survey is conducted to collect data from 216 academic journals users, including, university lecturers, academic journal professionals, and college students, after which, SPSS22.0 was used to investigate 20 factors that affect these users' experience in four indices, namely, the brand image of an academic journal, the academic performance of an academic journal, the frequency of using an academic journal in new media form by users, and the performance of an academic journal in new media form.[Result]: The studied factors can contribute to achieving positive dissemination effect of academic journals, and the participants rated the academic performance of an academic journal as the core element in the dissemination process.[Conclusion]:To maintain a positive dissemination effect, academic journals need to continuously improve their academic performance and keep up with the development of new media.
\end{abstract}

\section{Introduction}

In the past few decades, China has witnessed a rapid and healthy development of new media, especially the Mobile Internet. By the end of 2018, the universalisation rate of the Internet in China was 59.6\%, and the Mobile Internet usage rate reached as high as $98.6 \%{ }^{[1]}$. To catch the trend, Academic journals have made moves in digitalising their publications and opening new media platform for wider user connections. In 2017, the turnover of China's digital publishing industry reached 707.1 billion yuan ${ }^{[2]}$. The dissemination effect of academic journals is closely linked to the journals' circulation and income. However, the traditional way of evaluating the dissemination effect of academic journals failed to meet the standard of assessing digitalised publication in new media era. Thus, journal publishers and researchers need to take new media technology as a crucial factor to evaluate the dissemination effect of academic journals.

Previous studies conducted by journal professionals and scholars prove that the evaluation of the dissemination effect of academic journals in new media form is crucial and cutting-edge. For instance, Dai Yanling proposed an approach to improve the effectiveness of Academic journal dissemination by combining conventional distribution methods with new communication methods in three ways: expending the scope, increasing the depth, and securing the accuracy of a journal's dissemination ${ }^{[3]}$. Han Feifei, Wang Guoyan and Zhou Rongting advised another three ways to improve the dissemination effect of the online journal, namely, adding the evaluation index of Sci- tech journal network construction, expanding the valueadded Internet service of Sci-tech journals, and improving the management and operation ability of the journal website ${ }^{[4]}$. Maria Monopoli, et al. suggested to build a user-oriented evaluation system to assess the services of electronic journals ${ }^{[5]}$.

This study starts from obtaining the user's opinions towards the dissemination effect of academic journals in the context of new media through a survey, and then it investigates and analyses the factors that affect the dissemination of academic journals in the context of new media with the assistance of SPSS22.0. This study is crucial, as it empirically verifies the direction and intensity of each factor that influence the dissemination effect of academic journals, and it provides empirical research evidence and feasible schemes for improving the dissemination effect of academic journals.

\section{Theoretical framework}

Previously, researches have been conducted on the dissemination effects of academic journals in the context of new media, among these researches qualitative studies outnumbered the quantitative ones. For instance, Wang Yi, et al. made quantitative observations on the campus communication effects of digital publishing platforms in terms of network platform, publication status, and resource utilisation ${ }^{[6]}$. Zhao Wenqing, et al. conducted a quantitative analysis on the factors that influence the dissemination effect of academic journals on WeChat, and found that the publication time, order, and type all have a 
significant influence on the dissemination effect ${ }^{[7]} . \mathrm{Xu}$ Xiang argued that the total amount of comments and reposts are crucial indicators in measuring the effect of new media communication ${ }^{[8]}$. Wang Jiao created a fourdimension model to study the dissemination effect of digital publications, which includes content of journal articles, academic reviews, quality of the journals, and website performance ${ }^{[9]}$.

Communication effect refers to the collected changes observed in users' cognition, opinion, and behaviours after their receiving of information. Traditional media effect studies, such as the 'magic bullet theory' and 'limited effect theory' focused on examining the role of communicators ${ }^{[10]}$. It was not until the birth of the 'uses and gratifications theory' ${ }^{[11]}$ that the study of media effect began to explore the communication effect from audience's perspective. This study also focuses on studying media effect with an audience-oriented approach. According to the $5 \mathrm{~W}$ communication theory proposed by Laswell, one of the four pioneers of communication studies ${ }^{[12]}$, five key elements are involved in a communication process: "Who/says what/in what channel/to whom/with what effect?"However, a successful communication is determined by four factors, namely, the communicator, communicated information, media, and audience.

Based on previous research, this study emphasises on the study of audience's reflection to the dissemination effect of academic journals after the rise of new media. Thus, four measuring indices are involved, the brand image of an academic journal (communicator), the academic performance of an academic journal (communication), the frequency of using an academic journal in new media form by users (media), and the performance of an academic journal in new media form (media).

The sub-index of the brand image of an academic journal includes popularity, reputation, editorial standards, error rate, and printing quality. The sub-index of the academic performance of an academic journal includes authority, innovation, impact factor, funding ratio, and citation frequency. The sub-index of the frequency of using an academic journal in new media form by users includes, the number of visits, downloads, comments, search frequency, and repost frequency. The sub-index of the performance of an academic journal in new media form includes operational convenience, the layout and design, opening speed, safety, and stability. The full list of the index is shown in Figure 1.

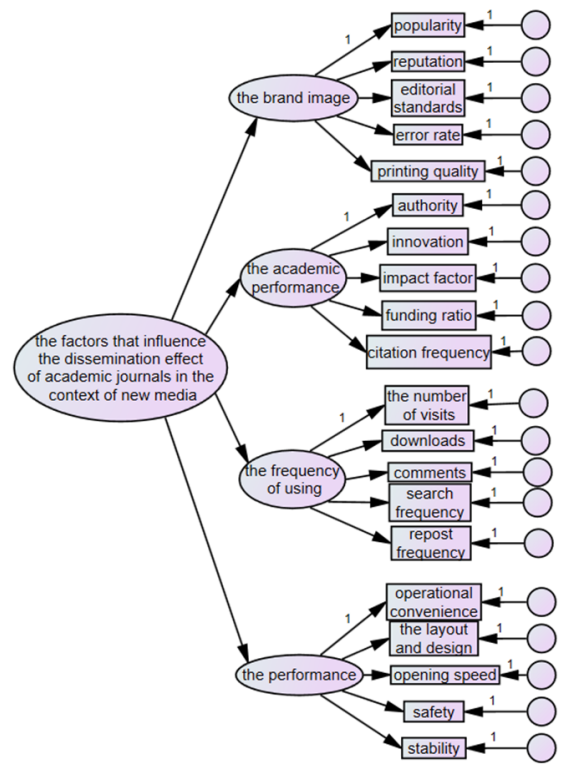

Figure 1 The index of the factors that influence the dissemination effect of academic journals in the context of new media

\section{Research hypothesis}

The brand image of an academic journal is closely linked to the numbers of users and subscribers. Thus, this study proposes: Hypothesis 1: There is a positive correlation between the brand image of an academic journal and the dissemination effect of academic journals in the context of new media.

The purpose of using academic journals for users is to acquire knowledge, so the academic performance of an academic journal determines whether users would choose a specific journal. Thus, this study proposes: Hypothesis 2: There is a positive correlation between the academic performance of an academic journal and the dissemination effect of academic journals in the context of new media.

The number of visits and downloads of academic journals in new media form are measurable factors that will affect the ranking and the communication effect of academic journals. Thus, this study proposes: Hypothesis 3: There is a positive correlation between the frequency of using an academic journal in new media form by users and the dissemination effect of academic journals in the context of new media.

New media has become another popular platform to access academic journals. The better performance of an academic journal in new media form, the better the dissemination effect will be achieved. Thus, this study proposes: Hypothesis 4: There is a positive correlation between the performance of an academic journal in new media form and the dissemination effect of academic journals in the context of new media.

\section{Research design and data collection}

\subsection{The design of the questionnaire survey}

The questionnaire is designed by taking Zhang Qianchu's 
study (2014) as a reference ${ }^{[13]}$, taking advices from Professor Shen Hao (Communication University of China), and referring to the theoretical framework shown in Figure 1.

Apart from collecting basic user information, the questionnaire set up 20 variables in four measuring indices (see Section 1. Theoretical framework paragraph 3) to measure users' satisfaction and the dissemination effect of academic journals in the context of new media. Specifically, 21 questions were designed with the reference to the 5-level scale of the Likert scale, and each question is set with five options to choose from: 1. Very dissatisfied, 2. Dissatisfied, 3. Not related, 4. Satisfied, 5. Very satisfied.

\subsection{Summary of collected data}

The survey was conducted online, and participants include, university lecturers, Academic journal professionals, and college students. A total of 221 questionnaires were returned, 5 invalid questionnaires were eliminated, and 216 valid questionnaires were collected as research data. Basic information of the participants is summarised as below:Gender: women accounted for $69.44 \%$, and men accounted for $30.56 \%$. Occupation: college lecturers accounted for $40.28 \%$, college students accounted for $34.72 \%$, government and enterprise employees accounted for $17.13 \%$, journalists accounted for $4.63 \%$, and researchers accounted for 3.24\%. Academic qualifications: undergraduates accounted for 51.39\%, postgraduates accounted for $34.26 \%$, specialists accounted for $7.87 \%$, and Ph.D. accounted for $6.48 \%$. The new media tools used to access scientific journals: mobile phones accounted for $71.3 \%$, and computers accounted for $28.7 \%$. Next, this study employs SPSS22.0 to conduct empirical analysis on 216 valid questionnaires.

\section{Data analysis}

\subsection{Reliability test}

Running reliability test is one of the commonly used methods to examine the consistency, stability, and the quality of questionnaires. In this study, Cronbach's $\alpha$, a widely used indicator for measuring reliability in SPSS, is used to conduct the test of 20 variables in four measuring indices (five variables in each index). The value of Cronbach's $\alpha$ coefficient is between 0 and 1 . If $\alpha$ coefficient can reach between 0.8 and 0.9 , the reliability of the scale is highly positive. The result is as follows: the brand image of an academic journal is 0.853 , the academic performance of an academic journal is 0.847 , the frequency of using an academic journal in new media form by users is 0.945 , and the performance of an academic journal in new media form is 0.917 . This proves that the questionnaire design of this study has passed the reliability test and the data collected from these questionnaires are credible to conduct the following research.

\subsection{Suitability test}

There are two tests used in this study to check the suitability of collected data for factor analysis. One is Kaiser-Meyer-Olkin Measure of Sampling Adequacy, or $\mathrm{KMO}$ in short. KMO is a statistic that indicates the proportion of variance in set variables that might be caused by underlying factors. High values (between 0.8 and 1.0) generally indicate that a factor analysis may be useful with data gathered from questionnaires in this study ${ }^{[15]}$. The other test is Bartlett's test of sphericity, which tests the hypothesis that the correlation matrix is an identity matrix. Small values (less than 0.05) of the significance level indicate that a factor analysis may be useful for this study.

By running Dimension Reduction with 20 set variables with SPSS 22.0. KMO is 0.939, which indicates that the 'Questionnaire on Factors Influencing the Dissemination Effect of academic Journals in the Context of New Media' is suitable for factor analysis. The approximate Chisquare value of Bartlett' test is 3649.286 , the Df value is 190 , and the significance probability value is $\mathrm{p}=0.000<0.05$, which indicates that the questionnaire is suitable for factor analysis. Thus, the questionnaire design of this study has passed the suitability test and can be expected to reveal the answer to the hypotheses proposed by this study.

\subsection{Factor analysis}

To determine the number of factors, this study uses SPSS22.0 to perform principal components analysis on the questionnaire data. According to Kaiser's varimax criterion for analytic rotation in factor analysis, the characteristic value of extracted factors should be greater than one. Table 1 below shows total variance explained of extracted factors, in terms of their characteristic value, variance and cumulation. In sum, the cumulative variability explained by these four factors in the extracted solution is $75.054 \%$.

Table1. Total variance explained, extracted factors

\begin{tabular}{|c|ccc|}
\hline \multirow{2}{*}{ Factor } & \multicolumn{3}{c|}{ Extraction Sums of Squared Loadings } \\
\cline { 2 - 4 } & Total & \multicolumn{3}{c|}{ \% of Variance } & Cumulative\% \\
\hline 1 & 11.247 & 56.236 & 56.236 \\
2 & 1.490 & 7.452 & 63.688 \\
3 & 1.266 & 6.329 & 70.017 \\
4 & 1.007 & 5.037 & 75.054 \\
\hline
\end{tabular}

Method: Principal Components Analysis

To investigate which questions in the questionnaire can better explain these 4 actors, this study runs Dimension Reduction Analysis on 20 variables with reference to Varimax with Kaiser Normalisation and $\alpha$ Rotation converged in 8 iterations. The results are shown in Table 2.

Table2. Rotated factor matrix

\begin{tabular}{|lllll|}
\hline \multicolumn{4}{|c|}{ Factor } \\
\cline { 2 - 5 } & 2 & 3 & 4 \\
\hline
\end{tabular}




\begin{tabular}{|lllll|}
\hline A1 & .653 & .209 & .370 & .321 \\
A2 & .649 & .286 & .331 & .320 \\
A3 & .623 & .459 & .084 & .330 \\
A4 & .771 & .191 & -.001 & .321 \\
A5 & .666 & .058 & .230 & .483 \\
B1 & .070 & .788 & .255 & .295 \\
B2 & .176 & .720 & .265 & .280 \\
B3 & .434 & .609 & .379 & .122 \\
B4 & .114 & .734 & .407 & -.073 \\
B5 & .475 & .620 & .356 & -.013 \\
C1 & .091 & .323 & .768 & .373 \\
C2 & .201 & .375 & .757 & .201 \\
C3 & .163 & .210 & .739 & .418 \\
C4 & .216 & .209 & .772 & .396 \\
C5 & .149 & .294 & .796 & .274 \\
D1 & .152 & .536 & .318 & .612 \\
D2 & .072 & .222 & .263 & .737 \\
D3 & .136 & .400 & .308 & .658 \\
D4 & .309 & .261 & .234 & .749 \\
D5 & .262 & .238 & .300 & .771 \\
\hline
\end{tabular}

Method: Principal Components Analysis

Rotation Method: Varimax with Kaiser Normalisation $\alpha$ Rotation converged in 8 iterations

Specifically, each one of the four factors has five subelements. That is, Factor 1 'the brand image of an academic journal' has five elements, namely, A1, A2, A3, A4, and A5. Factor 2 'the academic performance of an academic journal', has five elements, which are B1, B2, B3, B4, and B5. Factor 3 'the frequency of using an academic journal in new media form by users', has $\mathrm{C} 1, \mathrm{C} 2$, $\mathrm{C} 3, \mathrm{C} 4$, and $\mathrm{C} 5$. Factor 4 'the performance of an academic journal in new media form' contains D1, D2, D3, D4, and
D5. The analysed data proves that the influencing factors set in the indices can effectively reflect the attributes of the factors designed in the questionnaire.

\subsection{Linear Regression analysis}

The standardised regression coefficient is also called the $\beta$ value. The standardised regression coefficient is the regression coefficient after eliminating the influence of different units used by the dependent variable and the independent variable. The absolute value of the modified coefficient directly reflects the degree of influence of the independent variables on the dependent variables, this means that $\beta$ value can exposes the relationship between the independent variables and the dependent variables. After running a linear regression analysis with SPSS 22.0, this study has gained the statistics as Table 3 below shows.

In Table 3, all $\beta$ values are positive, which means that the prediction of four hypotheses holds true and four measuring indices listed in the table have positive correlation with the dissemination effect of academic journals. Specifically, the promotion of the brand image of an academic journal can improve the dissemination effect. Therefore, building a good brand image is one of the important tasks of scientific journals, as it closely linked to users' choices of reading. The academic performance of an academic journal is the core to achieve successful dissemination effect, thus, the professionals who work in the field should make great efforts in improving the quality of their publication.

Table3. Stepwise Coefficients Analysis Model Dependent variable: dissemination effect

\begin{tabular}{|c|c|c|c|c|c|}
\hline \multirow{2}{*}{ Model } & \multicolumn{2}{|c|}{$\begin{array}{l}\text { Unstandardised } \\
\text { Coefficients }\end{array}$} & \multicolumn{2}{|c|}{$\begin{array}{l}\text { Standardised } \\
\text { Coefficients }\end{array}$} & \multirow{2}{*}{ ig. } \\
\hline & B & rror & $\beta$ & & \\
\hline (constant) & -0.020 & 0.005 & & -3.920 & 0.000 \\
\hline Factor 1 & 0.252 & 0.002 & 0.282 & 142.684 & 0.000 \\
\hline Factor 2 & 0.253 & 0.002 & 0.266 & 133.091 & 0.000 \\
\hline Factor 3 & 0.251 & 0.002 & 0.307 & 159.798 & 0.000 \\
\hline Factor 4 & 0.250 & 0.002 & 0.284 & 149.637 & 0.000 \\
\hline
\end{tabular}

Dependent variable: dissemination effect

The frequency of using an academic journal in new media form by users also has a positive correlation with the dissemination effect of academic journals in the context of new media. The more often the dissemination of academic journals in new media, the easier it will be for users to access the journals. Academic journals should make full use of the advantage of promoting their publication through new media so that to improve the journals' dissemination effects.

The performance of an academic journal in new media form is another important indicator of the dissemination effect of academic journals. Participants of this questionnaire survey have a preference of using mobile phone with high frequency. This implies that Academic journal professionals should take the characteristics of the new media and users' habits into consideration and design a communication strategy that suits for mobile media environment.

\subsection{Checking model fit with regression function}

After getting the result from Table 4, it is important to check model fit between the regression coefficient and collected data in this study. To finish this task, the coefficient of determination $\left(\mathrm{R}^{2}\right)$ and the coefficient of determination for adjustment (adjusted $\mathrm{R}^{2}$ ) are examined in SPSS regression analysis. 
Table4. Model summary ${ }^{b}$

\begin{tabular}{|cccl|}
\hline Model & $\mathrm{R}$ & $\mathrm{R}^{2}$ & Adjusted $\mathrm{R}^{2}$ \\
\hline 1 & $0.946^{\mathrm{a}}$ & 0.895 & 0.892 \\
\hline
\end{tabular}

a.Predictors: (constant) The brand image of an academic journal

The academic performance of an academic journal The frequency of using an academic journal in new media form by users

The performance of an academic journal in new media form b. Dependent variables: the dissemination effect

As Table 4 above shows, the $\mathrm{R}^{2}$ for the 'dissemination effect' of the four independent variables and the dependent variable in this model is 0.895 , that is, the four variables can effectively explain $89.5 \%$ of the 'dissemination effect'. The number of regression independent variables will influence the $\mathrm{R}^{2}$. The more regression variables are set to analyse, the more interpretation of the result is needed. By adding the examination of adjusted $\mathrm{R}^{2}$, this study can investigate whether new variables in Figure 1 needs to be added. As a result, adjusted $\mathrm{R}^{2}$ is less than $\mathrm{R}^{2}$ in Table 4, thus, there is no need to add new independent variables. This indicates that the regression model fits the study, and it is unnecessary to add independent variables to explain the dependent variables.

To further confirm the validity of proposed hypotheses, a significance test is conducted with SPSS 22.0, as Table 6 below shows. On the significance level of 0.05, the Sig. of this study is 0.000 , therefore, the brand image of an academic journal, the academic performance of an academic journal, the frequency of using an academic journal in new media form by users, and the performance of an academic journal in new media form have strong influence over the dissemination effect of the journals, and the four hypotheses are valid.

\section{Conclusion of research result}

\subsection{Summary of research result}

This study empirically analysed four proposed factors that influence the dissemination effect of academic journals in the context of new media through a questionnaire survey. By conducting regression analysis of collected valid data, it can be concluded that the brand image of an academic journal, the academic performance of an academic journal, the frequency of using an academic journal in new media form by users and the performance of an academic journal in new media form are all positively correlated with the communication effect of academic journals. The influence of the four factors on communication effects is in order of academic performance, the frequency of new media, brand image, and new media performance.

\subsection{Suggestion on future practice of academic journals}

First, academic journals need to improve their academic performance. This study revealed that academic performance is the core factor influencing the dissemination effect of academic journals in the context of new media. Academic journals ought to take the responsibility of producing quality content with high standard for users.

Second, the rise of new media will inevitably lead to the transformation of academic journals. Academic journals must widen the dissemination of their publication on the Internet and continuously improve the performance of the new media the journals used. The boundary between new media and traditional media has inevitably blurred, which leads to the change of users' media usage habits. Academic journals should meet users' media usage needs by continuously updating the form of dissemination of their publication in new media era and further enhance the dissemination effect of the journals.

Finally, the brand image is an intangible asset for academic journals to improve their competitiveness in the market. Academic journals should employ a variety of methods to enhance their brand building, and even establish Corporate Identity Recognition System (CIS) if necessary. By creating a favourable brand image among the users, the academic journals can increase the number of visit online.

\section{References}

1. CNNIC 'Annual Report on the Development of China's Internet'. EB/OL] .[2019-3-2]. cnnic.cn/gywm/xwzx/rdxw/20172017_7056/201902/ t20190228_70643.htm.

2. 2017-2018 'Annual Report on China's Digital Publishing Industry' [ EB/OL ] [2019-3-2] http://www.cbbr.com.cn/article/123368.html.

3. Dai Yanling, Zhu Shuancheng, Yang Zhengka, Gong Zaiqin. 'A report on Examining the Means and Practices to Improve the Quality and Influence of Scitech Journals' [J]. Acta Editologica, 2017(03):222225.

4. Han Feifei,Wang Guoyan, Zhou Rongting. 'A Comparative Analysis of the Effects of Internet Communication of Top Science and Technology Journals in China' [J]. Publishing Research, 2015(07): 57-60.

5. Maria Monopoli, et al. A user-oriented evaluation of digital libraries:case study the "electronic journals" service of the library and information service of the University of Patras, Greece.[J]Aslib Proceedings, 2002,54(2):103-177.

6. Wang Yi, Chen Shihan, Liu Liming. 'A case study of evaluating the dissemination effect of different academic journal on digital publishing platforms in medical colleges: based on survey data from 4 medical colleges in Shaanxi Province' [J]. Journalism \& Communication, 2018(11):27-29.

7. Zhao Wenqing, Zong Minggang. 'A Case Study on the Influencing Factors of WeChat Communication Effect of academic Journals' [J].Chinese Journal of Scientific and Technological Periodicals, 2016, 
27(06):611-616.

8. Xu Xiang. 'An Empirical Analysis of the Communication Effects and Influencing Factors of the "Socialisation" of Chinese Media-Based on Microblog Sample Mining from 30 Media [J]. Social Science Journal of Harbin Institute of Technology, 2016(3):63-77.

9. Wang Jiao, Zhang Qianchu. 'Empirical Research on Countermeasure on the Factors Influencing the Quality of Online Publishing Journals' [J]. Information Science, 2015, 33(3):135-140.

10. Hu Zhnegrong. 'Introduction to Communication' [M]. Beijing, Communication University of China Press, 1997.

11. Zhang Qianchu. 'An empirical Research on The Influencing Factors on the Quality of Electronic Journals Published' [D].Chang Chun: Northeast Normal University,2014.

12. Ke Huixin, Shen Hao. 'Statistical Analysis handbook on Investigative Research' (Second Edition) [M]. Beijing, Communication University of China Press, 2005. 